\title{
Efficacy of Adoptive Immune-cell Therapy in Patients with Advanced Gastric Cancer: A Retrospective Study
}

\author{
RISHU TAKIMOTO, TAKASHI KAMIGAKI, SACHIKO OKADA, ERIKO MATSUDA, \\ HIROSHI IBE, ERI OGUMA, KEIKO NAITOH, KAORI MAKITA and SHIGENORI GOTO
}

Seta Clinic Group, Tokyo, Japan

\begin{abstract}
Background: Conventional therapy for advanced gastric cancer $(G C)$ has limited survival benefits. In this retrospective study, we aimed to investigate the efficacy of immune-cell therapy, using in vitro-activated $T$ lymphocytes with and without dendritic cells (DCs), in combination with standard therapies in terms of the survival of patients with advanced GC. Patients and Methods: A total of 242 patients who were diagnosed as having stage-IV GC were enrolled in this study to receive immune-cell therapy with or without standard therapies, such as chemotherapy, surgery, or radiation therapy. Overall survival was analyzed by the Kaplan-Meier with log-rank test and Cox regression methods. Results: Immune-cell therapy increased median survival time (21.5 months) in patients with advanced GC. The patients who underwent surgery with or without chemotherapy as a prior treatment showed better prognosis than those who received other therapies $(p<0.001)$. Patients who showed stable disease or a partial response to immune-cell therapy had a better prognosis than those with progressive disease $(p<0.001)$. Multivariate analysis revealed that performance status, the type of immune-cell therapy, and prior treatment were independent prognostic factors for patients with GC. No serious adverse event was reported in immune-cell therapy. Conclusion: Immune-cell therapy might extend the survival of patients with advanced $G C$.
\end{abstract}

Gastric cancer (GC) remains one of the leading causes of cancer-related deaths worldwide (1). Patients who are diagnosed at stages unsuitable for curative surgery have

Correspondence to: Rishu Takimoto, Director, Seta Clinic ShinYokohama, Seta Clinic Group, Shin-Yokohama Square Building 15F, 2-3-12 Shin-Yokohama, Kohoku-ku, Yokohama, Kanagawa 222-0033, Japan. Tel: +81 454780086, Fax: +81 454780087, e-mail: takimoto@j-immunother.com

Key Words: Immune-cell therapy, gastric cancer, chemotherapy, surgical operation. extremely poor prognoses, with 5-year survival rates ranging from 2 to $15 \%(2,3)$. Adoptive immune-cell therapy, a type of autologous activated lymphocyte therapy (ALT) (4), is currently the predominant immune-cell therapy in Japan. In this therapy, T-lymphocytes, mostly peripheral blood mononuclear cells, are activated and proliferated through a culture process involving stimulation with an immobilized antibody to CD3, and interleukin-2 (IL2), and repeatedly administered to patients without high-dose IL2 administration. This therapy has few severe adverse events.

Since the early 1990s, many university hospitals and cancer centers have been actively investigating the applicability of autologous ALT using lymphokine-activated killer cells (LAKs), tumor-infiltrating lymphocytes (TILs), cytotoxic lymphocytes (CTLs), CD3-LAKs, and dendritic cells (DCs) (4-7). Among them, the Seta Clinic Group, which includes four private clinics providing specialized type of immune-cell therapy in cooperation with cell-processing facilities, has treated more than 20,000 patients with cancer using immune-cell therapy over the past 17 years. Here, as part of our ongoing studies to improve response and survival rates in patients with progressive or advanced GC, we retrospectively investigated the efficacy of immune-cell therapy in the treatment of patients with advanced GC with or without other standard therapies.

\section{Patients and Methods}

Patients. Of the 957 patients with GC treated from 1 April, 1999 to 30 September, 2016, 582 underwent at least six cycles of immunecell therapy. Among them, we extracted data for 242 patients with clinical stage IV disease who were evaluated by diagnostic imaging and had sufficient clinical information available (Figure 1). Clinical stage was determined in accordance with the seventh edition of the Union for International Cancer Control using the tumor node metastasis (TNM) staging system for GC (8).

Treatment. Activated lymphocytes were generated as described elsewhere (9). Briefly, about $22.5 \mathrm{ml}$ of peripheral blood was obtained, and mononuclear cells (MNCs) were separated using a Vacutainer (Becton, Dickinson and Company, Franklin Lakes, NJ, USA). Following activation with an immobilized monoclonal 


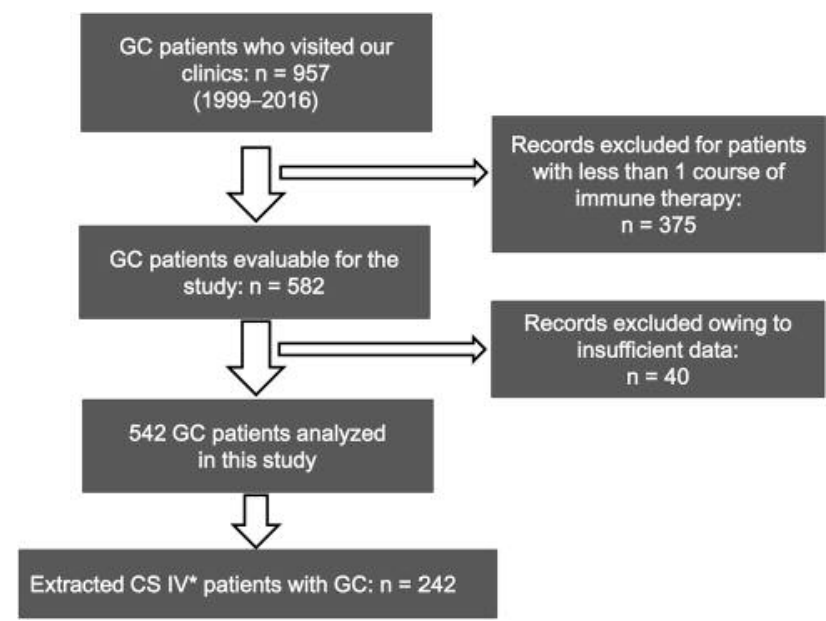

Figure 1. Selection procedure of clinical trials. CS: Clinical stage; *diagnosed by primary physician.

antibody to CD3 (Janssen-Kyowa, Tokyo, Japan) in HyMedium 930 (Kohjin Bio, Saitama, Japan) containing 1\% autologous serum, the MNCs were cultured for 2 weeks with $700 \mathrm{IU} / \mathrm{ml}$ recombinant IL2 (Proleukin ${ }^{\circledR}$; Chiron, Amsterdam, the Netherlands). After culture, 3$10 \times 10^{9}$ cells were harvested and suspended in $100 \mathrm{ml}$ of saline for intravenous injection. For DC generation, MNCs were collected by leukoapheresis, and MNCs were separated and allowed to adhere to a plastic culture flask in order to obtain adherent cells. After removing nonadherent cells, adherent cells were cultured with 50 $\mathrm{ng} / \mathrm{ml}$ granulocyte macrophage colony-stimulating factor (GM-CSF) (Primmune Corp., Osaka, Japan) and 50 ng/ml IL4 (Primmune Corp.) for 6 days to obtain immature DCs. The DCs were cultured with antigens appropriate for the patient's tumor and allowed to mature for 24 hours prior to administration. Approximately 1$10 \times 10^{6}$ mature DCs were then harvested and suspended in $1 \mathrm{ml}$ of saline for subcutaneous vaccination. Immune-cell therapy comprised single administration of lymphocytes, DCs, or both, approximately every 2 to 4 weeks.

Clinical response and assessment. Only patients with measureable lesions were included in the analysis. Responses were assessed according to the following definitions: a complete response (CR) indicated no assessable tumor with normalization of levels of tumor markers and laboratory values for at least 4 weeks; a partial response (PR) indicated a decrease in the size of all measured lesions by $30 \%$ or more of the initial diameter for at least 4 weeks, with no lesions increasing in size and no new lesions appearing; stable disease (SD) indicated a steady state or a response less than PR, but without disease progression for at least 4 weeks, with no new lesions appearing and no symptoms worsening; and progressive disease (PD) indicated an increase of $20 \%$ in a single dimension or in the sum of the products of perpendicular diameters of any measurable lesion. The time to progression and overall survival time were measured from time of initial diagnosis to the time of disease progression and time of death, respectively. The Kaplan-Meier method was used to calculate survival probabilities for all patients.
Table I. Patient characteristics.

\begin{tabular}{lc}
\hline Characteristic & Value \\
\hline Total, $\mathrm{n}$ & 242 \\
Male & 137 \\
Female & 105 \\
Median age (range), years & $62(26-91)$ \\
Performance status, $\mathrm{n}$ & \\
0 & 144 \\
1 & 63 \\
2 & 8 \\
3 & 12 \\
4 & 1 \\
Unknown & 14 \\
Histological differentiation, $\mathrm{n}$ & \\
Well & 25 \\
Moderate & 31 \\
Poor & 73 \\
Signet cell & 30 \\
Other & 4 \\
Unknown & 79 \\
Prior treatment, $\mathrm{n}$ & \\
Surgery & 107 \\
Radiation & 21 \\
Chemotherapy & 213 \\
Metastatic site, $\mathrm{n}$ & \\
Liver & 74 \\
Lymph node & 132 \\
Lung & 16 \\
Peritoneum & 125 \\
Bone & 19 \\
Other & 45 \\
\hline & \\
\hline & \\
& \\
&
\end{tabular}

Statistical analyses. Overall survival (OS) was analyzed by the Kaplan-Meier with log-rank test for univariate analysis and Cox regression methods for multivariate analysis. All statistical analyses were two-sided and performed using JMP, version 11.2.0 for Microsoft Windows 7 (SAS, Cary, NC, USA). Results were considered statistically significant when $p<0.05$.

\section{Results}

Patients. Of the 957 patients with GC treated from 1 April, 1999 to 30 September, 2016, we extracted data for 242 patients in clinical stage IV who were evaluated by diagnostic imaging and had sufficient information available (375 patients were excluded because of insufficient cycles of immune-cell therapy, and 40 were excluded owing to insufficient clinical records) (Figure 1). A total of 242 patients, comprising 137 males and 105 females, with an average age of 62 years (range $=26-91$ years) were studied. There was no significant difference in the distribution of age, sex, performance status (PS), pathological diagnosis, or prior treatment among the patients (Table I). Characteristics of immune-cell therapy are summarized in Table II. Two 


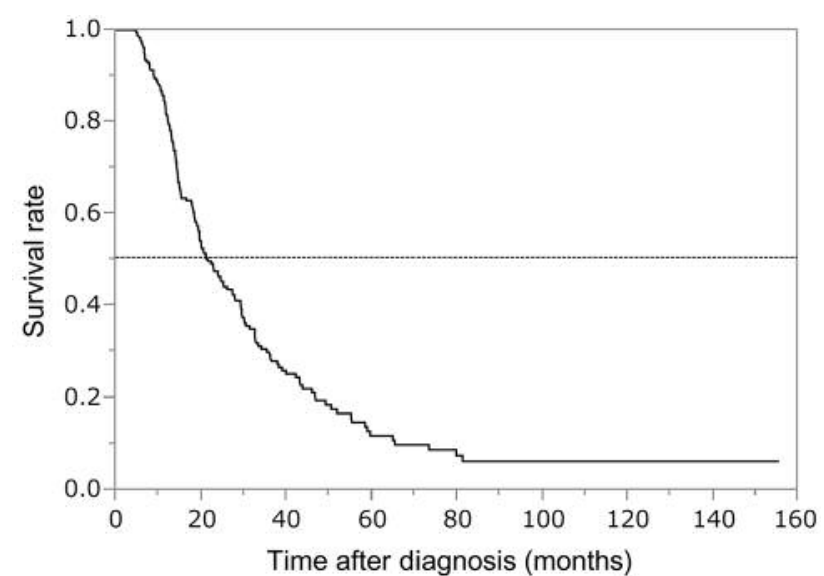

\begin{tabular}{|c|c|c|c|}
\hline \multirow{2}{*}{$\mathrm{N}$} & \multirow{2}{*}{$\begin{array}{c}\text { MST } \\
\text { (months) }\end{array}$} & \multicolumn{2}{|c|}{ Survival rate (\%) } \\
\cline { 3 - 4 } & & 3 Years & 5 Years \\
\hline 242 & $21.5(19.3-27.3)$ & 29.9 & 11.8 \\
\hline
\end{tabular}

Figure 2. Cumulative survival rate of patients with gastric cancer. MST, Median survival time (95\% confidence interval).

hundred and thirty-six patients $(97.5 \%)$ received $\alpha \beta$ T-cell therapy. Regarding DC vaccination therapy, eight patients received lysate-pulsed DCs and 31 received synthetic peptide-loaded DCs.

Treatment efficacy. The overall survival of the patients with GC in this study is shown in Figure 2. The median survival time was 21.5 months (95\% confidence interval=19.3-27.3 months). The 3- and 5-year survival rates of all patients with clinical stage IV GC seemed to be higher than those of the historical control group, as determined from the cancer survival rate of the Japanese Association of Clinical Cancer Center (https://kapweb.chiba-cancer-registry.org/) (3-year survival rate: immune-cell therapy group, $29.9 \%$ vs. historical control group, 10.8\%; 5-year survival rate: immune-cell therapy group, $11.8 \% \mathrm{vs}$. historical control group, $7.3 \%$ ). We first evaluated the effect of prior treatment on the survival rate of patients with GC. It was found that patients in the groups treated with surgery alone and surgery with chemotherapy had a significantly better prognosis than those in the chemotherapy-alone group in terms of median OS $(p<0.0001)$ (Table III, Figure 3$)$. Note that we found better prognosis for the surgically treated group than the historical control group on the basis of the cancer survival rates of the Japanese Association of Clinical Cancer Center, although we cannot statistically compare these survival rates. However, we did not find any benefits from chemotherapy, radiation therapy, or chemoradiation therapy in combination with immune-cell therapy at our clinics,
Table II. Types of adoptive immune-cell therapy.

\begin{tabular}{lc}
\hline Type & Number of patients \\
\hline ALT & 236 \\
$\alpha \beta$ T-Cells & 12 \\
$\gamma \delta$ T-Cells & 3 \\
NK & 11 \\
CTL & \\
DC & 8 \\
Lysate-pulsed & 31 \\
Synthetic peptide-loaded & 0 \\
No antigen & 41 \\
ALT+DC & \\
\hline
\end{tabular}

ALT: Activated lymphocyte therapy; NK: natural killer cells; CTL: cytotoxicT-lymphocytes. DC: dendritic cell vaccination therapy.

probably owing to the small number of patients in each group (Figure 4A). Furthermore, the efficacy of chemotherapeutic agents for advanced GC in combination with immune-cell therapy was not significantly different from that of conventional chemotherapeutic agents such as cisplatin, tegafur/gimeracil/oteracil (TS-1), and their combinations (Figure 4B).

When the effect of Eastern Cooperative Oncology Group (ECOG) PS on overall survival was assessed, we found that patients with PS 0 benefited from immune-cell therapy, showing a median survival of 24.5 months, which was longer than those in the other PS groups (Figure 5A).

However, the pathological diagnosis of tumor tissue did not have any effects on survival rate after immune-cell therapy (Figure 5B).

The clinical response to immune-cell therapy also significantly affected the prognosis of patients with advanced GC (Figure 6).

Finally, we examined the effect of the type of immune-cell therapy on the prognosis of patients with GC. As shown in Figure 7, patients who were mainly treated with ALT had better prognosis than those treated with other types, such as DC or DC with ALT.

We performed multivariate analysis of age and sex of patients, histological differentiation type, clinical stage, surgery, and immunotherapy using the Cox regression model to identify independent prognostic factors for advanced GC. The results showed that prior treatment and clinical response were independent prognostic factors (Table IV). As shown in Table V, when we examined 12 patients who survived longer than 5 years after diagnosis, 11 out of the 12 had one of the prognostic factors and eight out of the 12 had undergone surgery as a prior therapy, which was one of the independent prognostic factors for improved survival. 
Table III. Univariate and multivariate analyses of overall survival.

\begin{tabular}{|c|c|c|c|}
\hline \multirow[t]{2}{*}{ Characteristics } & \multirow[t]{2}{*}{ Parameter } & \multicolumn{2}{|c|}{$p$-Value } \\
\hline & & Univariate* & Multivariate ${ }^{* *}$ \\
\hline Sex & $\mathrm{M} v s . \mathrm{F}$ & 0.2742 & \\
\hline Age, years & $<65 v s . \geq 65$ & 0.3762 & \\
\hline Prior treatment & Surgery $v s$. chemotherapy $v s$. both & $<0.0001$ & 0.0307 \\
\hline Combination therapy & Chemotherapy $v s$. no therapy & 0.3782 & \\
\hline PS & $0 v s . \geq 1$ & 0.0329 & 0.1139 \\
\hline Histological differentiation & Poor $v s$. moderate $v s$. well & 0.7703 & \\
\hline Immune-cell therapy & $\mathrm{DC} v s . \mathrm{DC}+\mathrm{ALT} v s . \mathrm{ALT}$ & 0.0302 & 0.0590 \\
\hline Clinical response & $\mathrm{PR}+\mathrm{SD} v s . \mathrm{PD}$ & 0.0095 & 0.0419 \\
\hline
\end{tabular}

M, Male; F, female; Poorly, poorly differentiated adenocarcinoma; Moderate, moderately differentiated adenocarcinoma; Well, well-differentiated adenocarcinoma; DC, dendritic cell vaccination therapy; ALT, activated lymphocyte therapy; PR, partial response; SD, stable disease; PD, progressive disease. By *log-rank analysis, **Cox regression analysis.

\section{Discussion}

$\mathrm{GC}$ is a common form of cancer and one of the most frequent causes of cancer-related deaths worldwide $(1,10)$. Although the efficacy of GC treatment has been improved by the multiple disciplinary team approach, many patients with GC have a poor prognosis owing to relapse or metastasis, especially for those with advanced stage disease. Conventional treatments, including surgery, chemotherapy, and radiation therapy, may induce a variety of adverse effects and impair antitumor immunity, resulting in tumor cells remaining and relapse of disease (11).

It has been proposed that adoptive immune-cell therapy can stimulate and restore antitumor immunity because immune cells have the ability to recognize and kill tumor cells (12). Several types of adoptive immune-cell therapy have been used in the treatment of solid tumors, including GC, with increased efficacy, particularly in malignancies with poor response to traditional therapies (13-18). Furthermore, Shen et al. performed a systemic review and meta-analysis of nine eligible trials of GC and recently reported that adoptive immune-cell therapy in combination with adjuvant therapy resulted in significantly higher OS rates and progression-free survival, suggesting that immunecell therapy is indeed beneficial for those with advanced GC (19). In our study, immune-cell therapy plus surgery, both with and without chemotherapy, extended the median survival of patients with advanced GC by 32.6 and 31.4 months, respectively, compared with the chemotherapy-alone group (15.1 months), indicating that immune-cell therapy is beneficial for advanced GC.

However, it has been reported that various factors determine the clinical outcome of immune-cell therapy for patients with GC. Firstly, the immunogenicity of tumor antigens and effective presentation of antigens are important

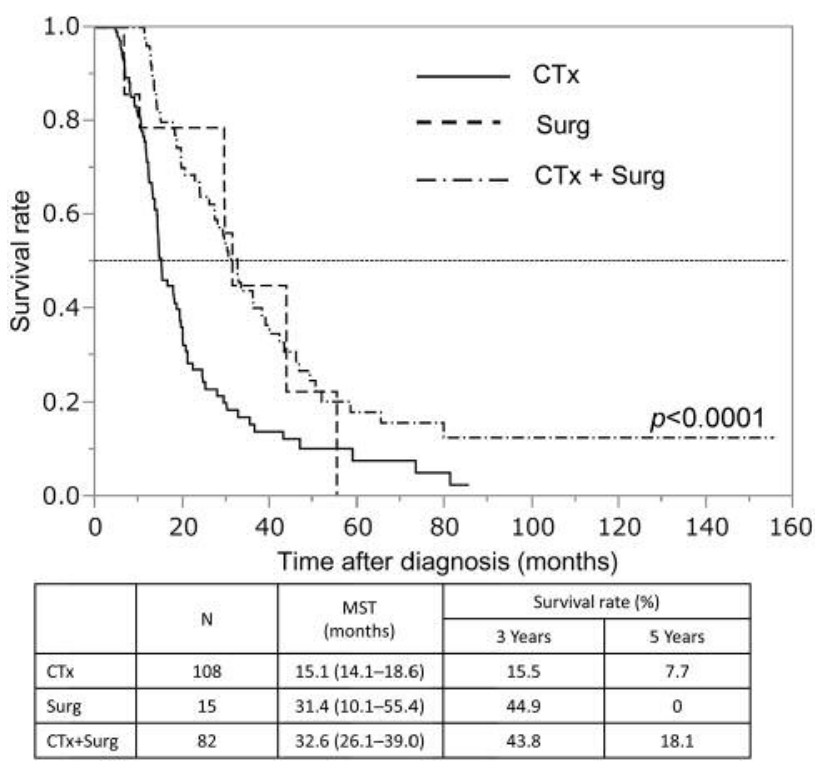

Figure 3. Cumulative survival rate in relation to treatment strategy. CTx, Chemotherapy; Surg, surgery; MST, median survival time (95\% confidence interval).

factors for antitumor immunity. Secondly, the quantity and quality of immune cells are also important factors affecting the efficacy of immune-cell therapy (20). Finally, solid tumors have a complex and inflamed microenvironment. The inflammation is induced via pro-inflammatory mediators secreted from tumors, TILs, cancer-associated fibroblasts, and myeloid-derived suppressor cells (MDSCs) (21). These cells have been shown to cross-talk with each other, resulting in the release of pro-inflammatory cytokines, chemokines, and 

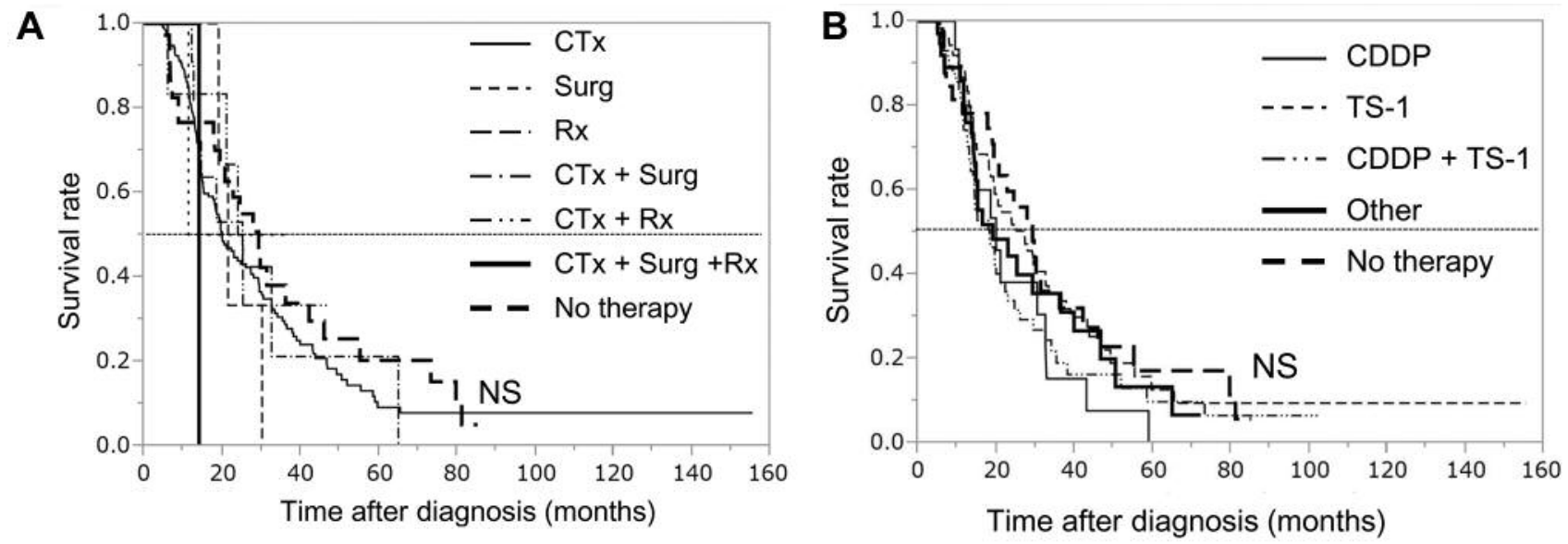

\begin{tabular}{|c|c|c|c|c|}
\hline \multirow{2}{*}{ Therapy } & \multirow{2}{*}{$\mathrm{N}$} & \multirow{2}{*}{$\begin{array}{c}\text { MST } \\
\text { (months) }\end{array}$} & \multicolumn{2}{|c|}{ Survival rate (\%) } \\
\cline { 4 - 5 } & & & 3 Years & 5 Years \\
\hline CTx & 182 & $20.0(18.0-27.3)$ & 29.6 & 9.2 \\
\hline Surg & 2 & $--(11.4--)$ & 50.0 & -- \\
\hline Rx & 3 & $21.5(19.1-30.2)$ & 0 & 0 \\
\hline CTx+Surg & 11 & $25.2(12.7-32.6)$ & 21.2 & 21.2 \\
\hline CTx+Rx & 6 & $24.7(6.1--)$ & 33.3 & -- \\
\hline CTx+Surg+Rx & 1 & $14.1(---)$ & 0 & 0 \\
\hline No therapy & 37 & $29.3(19.4-42.2)$ & 38.1 & 20.3 \\
\hline
\end{tabular}

\begin{tabular}{|l|c|c|c|c|}
\hline \multirow{2}{*}{ Therapy } & \multirow{2}{*}{$\mathrm{N}$} & \multirow{2}{*}{$\begin{array}{c}\text { MST } \\
\text { (months) }\end{array}$} & \multicolumn{2}{|c|}{ Survival rate (\%) } \\
\cline { 4 - 5 } & & & 3 Years & 5 Years \\
\hline CDDP & 17 & $20.0(11.7-32.6)$ & 15.2 & 0 \\
\hline TS-1 & 92 & $27.3(19.6-32.7)$ & 35.6 & 12.6 \\
\hline CDDP+TS-1 & 61 & $18.3(14.1-22.3)$ & 19.0 & 9.8 \\
\hline Other & 37 & $19.1(14.2-36.5)$ & 35.4 & 13.3 \\
\hline No therapy & 35 & $29.3(19.4-36.2)$ & 36.0 & 17.1 \\
\hline
\end{tabular}

Figure 4. Cumulative survival rate in relation to combination therapy (A) and chemotherapy protocol (B). CTx, Chemotherapy; Surg, surgery; Rx, radiation; CDDP, cisplatin; TS1, tegafur/gimeracil/oteracil; MST, median survival time (95\% confidence interval).

growth factors that induce immune suppression (21-23). It has been demonstrated that inhibition of the interaction between tumor cells and MDSCs might improve immune system function (24). Regarding this point, removal of tumor by surgical resection might result in the recovery from immune system dysfunction induced by MDSCs, leading to better prognosis. Moreover, surgery can markedly reduce the tumor burden, thus promoting survival (25). Treatment with immune cells can lead to the recovery of immunosuppressive status after surgery and provide survival benefits for patients who have undergone radical surgery.

Depending on the modality of chemotherapy, certain benefits were observed during immune-cell therapy. Since the patients enrolled in this study received a variety of anticancer drugs such as TS-1, cisplatin, and others, each group classified according to the drug administered consisted of a small number of patients. Thus, it might be difficult to obtain statistically significant differences or benefits from chemotherapy.

It has been reported in recent studies that immune checkpoint inhibitors such as ipilimumab and tremelimumab [antibodies to cytotoxic T-lymphocyte-associated protein 4
Table IV. Hazard risk analysis of independent prognostic factors for overall survival.

\begin{tabular}{lccc}
\hline Factor & HR & $95 \%$ CI & $p$-Value \\
\hline Prior treatment & & & \\
$\quad$ Surgery & 0.358 & $0.086-0.998$ & 0.0496 \\
$\quad$ Surgery + chemotherapy & 0.593 & $0.372-0.936$ & 0.0248 \\
Clinical response & 0.616 & $0.391-0.982$ & 0.0419 \\
\hline
\end{tabular}

CI: Confidence interval; HR: hazard ratio.

(CTLA-4)], and antibodies to programmed cell death 1 (PD1) or programmed cell death 1 ligand 1 (PDL1) (e.g. nivolumab and pembrolizumab) enhance local immune responses, resulting in tumor reduction by immune cells (26). Recently, Muro et al. showed that pembrolizumab is active in pretreated patients with GC with PDL1-expressing tumors (27). In order to improve the efficacy of immunecell therapy, its use in combination with these immune check-point inhibitors should be a promising strategy for advanced GC. 

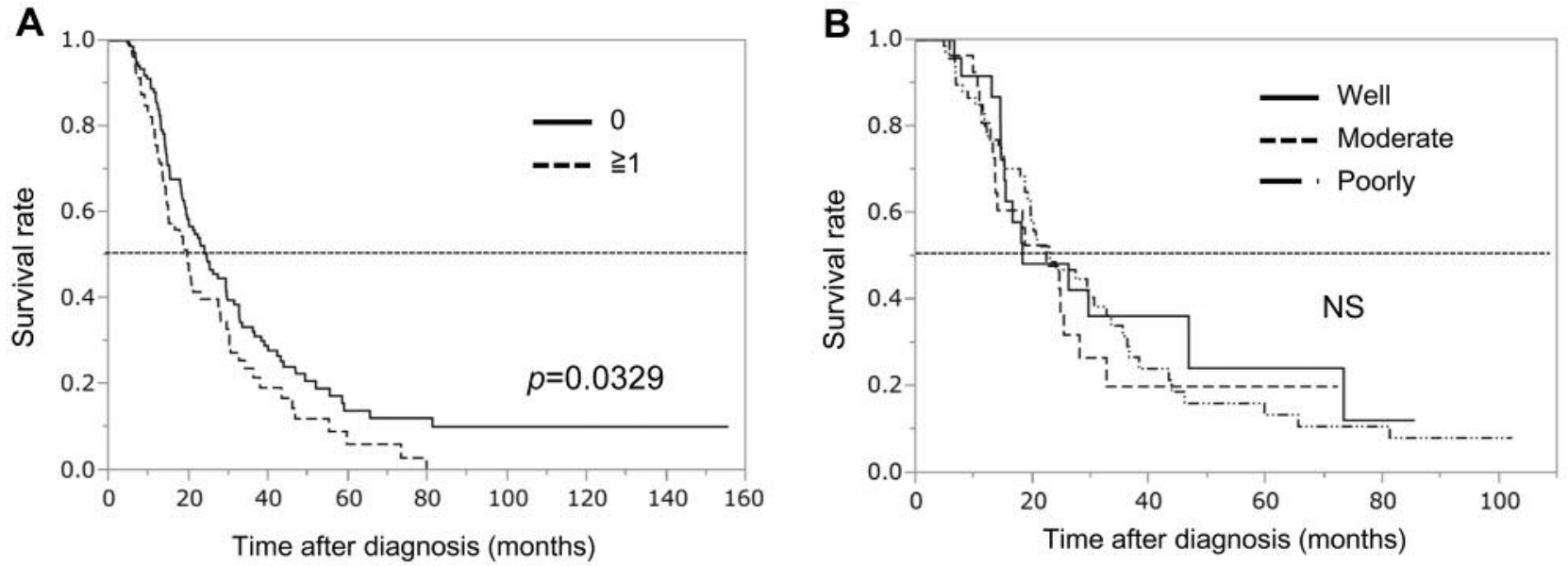

\begin{tabular}{|l|c|c|c|c|}
\hline \multirow{2}{*}{ PS } & \multirow{2}{*}{$\mathrm{N}$} & \multirow{2}{*}{$\begin{array}{c}\text { MST } \\
\text { (months) }\end{array}$} & \multicolumn{2}{|c|}{ Survival rate (\%) } \\
\cline { 4 - 5 } & & & 3 Years & 5 Years \\
\hline 0 & 144 & $24.5(19.6-29.5)$ & 33.3 & 13.8 \\
\hline$\geqq 1$ & 84 & $19.6(14.6-27.4)$ & 23.7 & 6.0 \\
\hline
\end{tabular}

\begin{tabular}{|l|c|c|c|c|}
\hline \multirow{2}{*}{ Histology } & \multirow{2}{*}{$\mathrm{N}$} & \multirow{2}{*}{$\begin{array}{c}\text { MST } \\
\text { (months) }\end{array}$} & \multicolumn{2}{|c|}{ Survival rate (\%) } \\
\cline { 4 - 5 } & & & 3 Years & 5 Years \\
\hline Well & 25 & $18.2(14.5-46.7)$ & 36.2 & 24.1 \\
\hline Moderate & 31 & $22.3(13.5-28.0)$ & 19.9 & 19.9 \\
\hline Poorly & 73 & $23.0(19.1-32.6)$ & 31.5 & 13.3 \\
\hline
\end{tabular}

Figure 5. Cumulative survival rate in relation to performance status (A) and histopathological findings (B). PS, Performance status; Well, Welldifferentiated adenocarcinoma; Moderate, moderately differentiated adenocarcinoma; Poorly, poorly differentiated adenocarcinoma; MST, median survival time (95\% confidence interval).

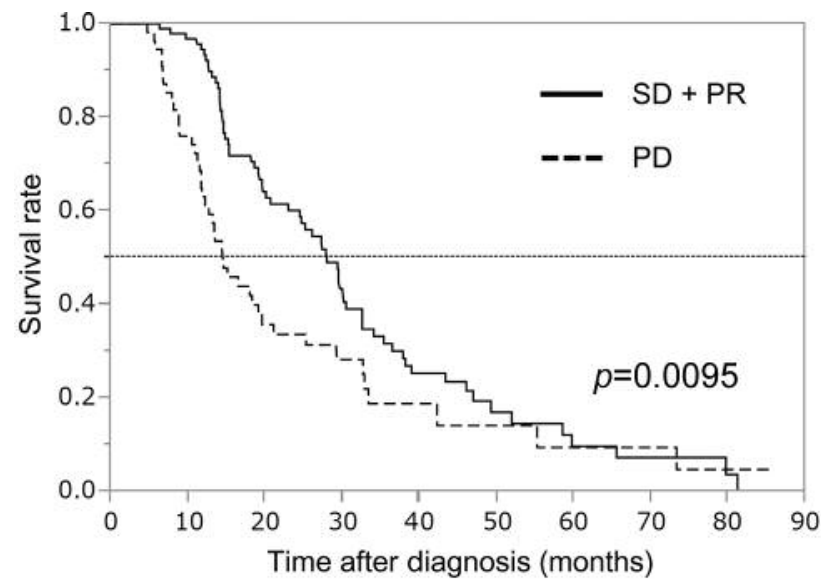

\begin{tabular}{|l|c|c|c|c|}
\hline \multirow{2}{*}{$\begin{array}{l}\text { Clinical } \\
\text { response }\end{array}$} & \multirow{2}{*}{$\mathrm{N}$} & \multirow{2}{*}{$\begin{array}{c}\text { MST } \\
\text { (months) }\end{array}$} & \multicolumn{2}{|c|}{ Survival rate (\%) } \\
\cline { 4 - 5 } & & & 3 Years & 5 Years \\
\hline SD+PR & 100 & $28.0(23.0-30.5)$ & 31.6 & 9.7 \\
\hline PD & 56 & $14.5(11.8-19.6)$ & 18.8 & 9.4 \\
\hline
\end{tabular}

Figure 6. Cumulative survival rate in relation to clinical response to immune-cell therapy. SD, Stable disease; $P R$, partial response; $P D$, progressive disease; MST, median survival time $(95 \%$ confidence interval).

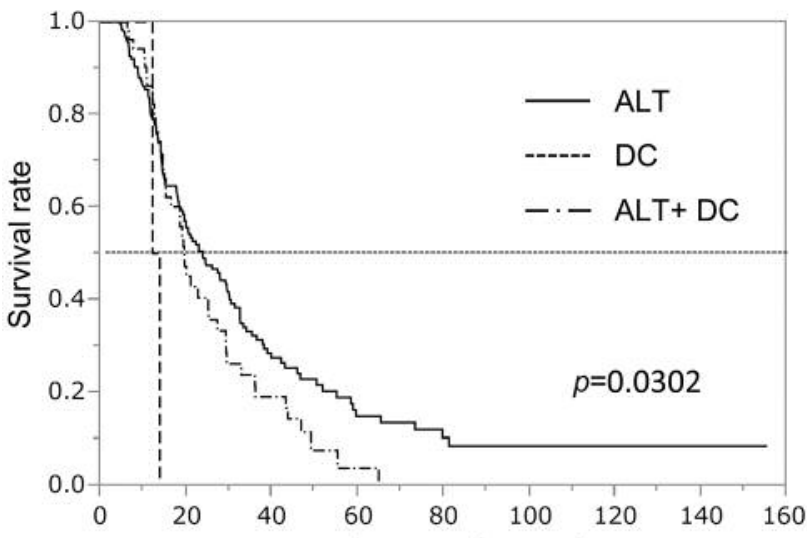

Time after diagnosis (months)

\begin{tabular}{|l|c|c|c|c|}
\hline \multirow{2}{*}{} & \multirow{2}{*}{$\mathrm{N}$} & \multirow{2}{*}{$\begin{array}{c}\text { MST } \\
\text { (months) }\end{array}$} & \multicolumn{2}{|c|}{ Survival rate (\%) } \\
\cline { 4 - 5 } & & & 3 -year & 5 -year \\
\hline ALT & 188 & $23.9(19.6-29.7)$ & 32.3 & 14.9 \\
\hline DC & 2 & $13.1(12.2-13.9)$ & 0 & 0 \\
\hline ALT+DC & 52 & $19.6(15.3-25.3)$ & 23.8 & 3.8 \\
\hline
\end{tabular}

Figure 7. Cumulative survival rate in relation to type of immune-cell therapy (ICT). ALT, Activated lymphocyte therapy; DC, dendritic cell vaccination therapy; MST, median survival time (95\% confidence interval). 
Table V. Characteristics of patients who survived longer than 5 years.

\begin{tabular}{lccccccccc}
\hline Case no. & Sex & $\begin{array}{c}\text { Age, } \\
\text { years }\end{array}$ & PS & $\begin{array}{c}\text { No. of } \\
\text { treatments }\end{array}$ & $\begin{array}{c}\text { Immune-cell } \\
\text { therapy }\end{array}$ & $\begin{array}{c}\text { Prior } \\
\text { treatment }\end{array}$ & $\begin{array}{c}\text { Clinical } \\
\text { response }\end{array}$ & $\begin{array}{c}\text { OS } \\
\text { (months) }\end{array}$ \\
\hline 1 & M & 59 & ND & 6 & ALT & Surg/CTx & NE & 74.9 & Survived \\
2 & F & 26 & ND & 6 & DC+ALT & None & NE & 65.0 & Dead \\
3 & F & 74 & 0 & 17 & ALT & CTx & PR & 81.2 & Dead \\
4 & M & 69 & 0 & 24 & ALT & Surg/CTx & SD & 72.3 & Survived \\
5 & M & 55 & 1 & 7 & ALT & CTx & PD & 73.3 & Dead \\
6 & F & 56 & 3 & 6 & ALT & Surg/CTx & SD & 79.7 & Dead \\
7 & F & 66 & 0 & 17 & ALT & Surg/CTx & NE & 155.5 & Survived \\
8 & M & 83 & 0 & 12 & ALT & CTx & PD & 85.5 & Survived \\
9 & M & 52 & 0 & 10 & ALT & Surg/CTx & NE & 102.2 & Survived \\
10 & M & 55 & 0 & 10 & ALT & Surg/CTx & NE & 85.2 & Survived \\
11 & F & 57 & 0 & 6 & ALT & Surg/CTx & NE & 91.0 & Survived \\
12 & F & 43 & 0 & 18 & ALT & Surg/CTx & SD & 65.5 & Dead \\
\hline
\end{tabular}

ALT, Activated lymphocyte therapy; CTx, chemotherapy; DC, dendritic cell vaccination therapy; ND, not determined; NE, not evaluable; PD, progressive disease; PR, partial response; PS: performance status at first visit; SD, stable disease; Surg, surgery.

Finally, there are several limitations to this study. Firstly, the patients were enrolled from a single center; therefore, a multicenter prospective study is required for confirming the general effects of immune-cell therapy. A randomized trial should be conducted to further evaluate the benefits of immune-cell therapy. Lastly, the number of patients also limits the quality of results for further evaluation of the significance of immune-cell therapy in patients with stage IV GC.

\section{Disclosure}

The Authors report no conflicts of interest in regard to this work.

\section{References}

1 Ferlay J, Shin HR, Bray F, Forman D, Mathers C and Parkin DM: Estimates of worldwide burden of cancer in 2008: GLOBOCAN 2008. Int J Cancer 127: 2893-2917, 2010.

2 Wagner AD, Grothe W, Haerting J, Kleber G, Grothey A and Fleig WE: Chemotherapy in advanced gastric cancer: a systematic review and meta-analysis based on aggregate data. J Clin Oncol 24: 2903-2909, 2006.

3 Lordick F and Janjigian YY: Clinical impact of tumour biology in the management of gastroesophageal cancer. Nat Rev Clin Oncol 13: 348-360, 2016.

4 Egawa K: Immuno-cell therapy of cancer in Japan. Anticancer Res 24: 3321-3326, 2004.

5 Rosenberg SA: The adoptive immunotherapy of cancer using the transfer of activated lymphoid cells and interleukin-2. Semin Oncol 13: 200-206, 1986.

6 Banchereau J, Palucka AK, Dhodapkar M, Burkeholder S, Taquet N, Rolland A, Taquet S, Coquery S, Wittkowski KM, Bhardwaj N, Pineiro L, Steinman R and Fay J: Immune and clinical responses in patients with metastatic melanoma to CD34(+) progenitor-derived dendritic cell vaccine. Cancer Res 61: 6451-6458, 2001.
7 Takayama T, Sekine T, Makuuchi M, Yamasaki S, Kosuge T, Yamamoto J, Shimada K, Sakamoto M, Hirohashi S, Ohashi Y and Kakizoe T: Adoptive immunotherapy to lower postsurgical recurrence rates of hepatocellular carcinoma: a randomised trial. Lancet 356: 802-807, 2000.

8 Sobin LH, Gospodarowicz MK and Wittekind C: International Union Against Cancer (UICC) TNM Classification of Malignant Tumours, Seventh Ediition. New York: Wiley-Liss, pp. 1-336, 2009.

9 Rosenberg SA, Spiess P and Lafreniere R: A new approach to the adoptive immunotherapy of cancer with tumor-infiltrating lymphocytes. Science 233: 1318-1321, 1986.

10 Siegel R, Naishadham D and Jemal A: Cancer statistics, 2013. CA Cancer J Clin 63: 11-30, 2013.

11 Lee K, Hwang H and Nam KT: Immune response and the tumor microenvironment: how they communicate to regulate gastric cancer. Gut Liver 8: 131-139, 2014.

12 Schmidt-Wolf GD and Negrin RS and Schmidt-Wolf IG: Activated T-cells and cytokine-induced $\mathrm{CD} 3{ }^{+} \mathrm{CD} 56^{+}$killer cells. Ann Hematol 74: 51-56, 1997.

13 Kono K, Takahashi A, Ichihara F, Amemiya H, Iizuka H, Fujii $\mathrm{H}$, Sekikawa $\mathrm{T}$ and Matsumoto Y: Prognostic significance of adoptive immunotherapy with tumor-associated lymphocytes in patients with advanced gastric cancer: a randomized trial. Clin Cancer Res 8: 1767-1771, 2002.

14 Cheever MA and Higano CS: PROVENGE (Sipuleucel-T) in prostate cancer: the first FDA-approved therapeutic cancer vaccine. Clin Cancer Res 17: 3520-3526, 2011.

15 Mann DL, Celluzzi CM, Hankey KG, Harris KM, Watanabe R and Hasumi K: Combining conventional therapies with intratumoral injection of autologous dendritic cells and activated T-cells to treat patients with advanced cancers. Ann N Y Acad Sci 1174: 41-50, 2009.

16 Hunder NN, Wallen H, Cao J, Hendricks DW, Reilly JZ, Rodmyre R, Jungbluth A, Gnjatic S, Thompson JA and Yee $\mathrm{C}$ : Treatment of metastatic melanoma with autologous CD4+ T-cells against NY-ESO-1. N Engl J Med 358: 2698-2703, 2008. 
17 Du XH, Liu HL, Li L, Xia SY, Ning N, Zou ZY, Teng D, Xiao $\mathrm{CH}, \mathrm{Li} \mathrm{R}$ and $\mathrm{Xu} Y \mathrm{X}$ : Clinical significance of immunotherapy with combined three kinds of cells for operable colorectal cancer. Tumour Biol 36: 5679-5685, 2015.

18 Kuai J, Yang F, Li GJ, Fang XJ and Gao BQ: In vitro-activated tumor-specific $\mathrm{T}$ lymphocytes prolong the survival of patients with advanced gastric cancer: a retrospective cohort study. Onco Targets Ther 9: 3763-3770, 2016.

19 Shen D, Liu ZH, Xu JN, Xu F, Lin QF, Lin F and Mao WD: Efficacy of adoptive cellular therapy in patients with gastric cancer: a meta-analysis. Immunotherapy 8: 971-981, 2016.

20 Goldberg JL and Sondel PM: Enhancing cancer immunotherapy via activation of innate immunity. Semin Oncol 42: 562-572, 2015.

21 Gabrilovich DI, Ostrand-Rosenberg $\mathrm{S}$ and Bronte V: Coordinated regulation of myeloid cells by tumours. Nat Rev Immunol 12: 253-268, 2012.

22 Yang L, Pang Y and Moses HL: TGF-beta and immune cells: an important regulatory axis in the tumor microenvironment and progression. Trends Immunol 31: 220-227, 2010.

23 Viola A, Sarukhan A, Bronte V and Molon B: The pros and cons of chemokines in tumor immunology. Trends Immunol 33: 496504, 2012.

24 Beury DW, Parker KH, Nyandjo M, Sinha P, Carter KA and Ostrand-Rosenberg S: Cross-talk among myeloid-derived suppressor cells, macrophages, and tumor cells impacts the inflammatory milieu of solid tumors. J Leukoc Biol 96: 1109$1118,2014$.
25 Cuschieri A, Weeden S, Fielding J, Bancewicz J, Craven J, Joypaul V, Sydes M and Fayers P: Patient survival after D1 and D2 resections for gastric cancer: long-term results of the MRC randomized surgical trial. Surgical Co-operative Group. Br J Cancer 79: 1522-1530, 1999.

26 Barbee MS, Ogunniyi A, Horvat TZ and Dang TO: Current status and future directions of the immune checkpoint inhibitors ipilimumab, pembrolizumab, and nivolumab in oncology. Ann Pharmacother 49: 907-937, 2015.

27 Muro K, Chung HC, Shankaran V, Geva R, Catenacci D, Gupta S, Eder JP, Golan T, Le DT, Burtness B, Mcree AJ, Lin CC, Pathiraja K, Lunceford J, Emancipator K, Juco J, Koshiji M and Bang YJ: Pembrolizumab for patients with PD-L1-positive advanced gastric cancer (KEYNOTE-012): a multicentre, openlabel, phase 1b trial. Lancet Oncol 17: 717-726, 2016.

Received May 2, 2017

Revised May 29, 2017

Accepted May 30, 2017 